\title{
The Design of Augmented Reality Using Unity 3D Image Marker Detection for Smart Bus Transportation
}

\author{
https://doi.org/10.3991/ijim.v15i17.22071 \\ Murizah Kassim $^{(\bowtie)}$, Ahmad Syafiq Aiman A. Bakar \\ Universiti Teknologi MARA, Selangor, Malaysia \\ murizah@uitm.edu.my
}

\begin{abstract}
Public bus transportation has become an integral part of society which the disruption of bus services is one of the major concerns. This research presents a development of smart bus transportation using augmented reality (TRANSPAR) on a mobile application. One of the issues with public transportation is real-time responsiveness. Most bus schedules have presented online but customers still faced many failures. Some bus schedules are not updated when changes happened over time. Some existing bus schedules system are fixed to the bus stations. The research objective is to design an Augmented Reality application based on identified characteristics by using Unity 3D image marker detection on a mobile Android platform. The TRANSPAR is developed by using Vuforia and Google Firebase for acquiring the bus timetables. The phone camera is applied for marker image detection and scanning the bus station's images. AR and normal image scanners were designed. Google Firebase Database is used to retrieve and store each timetable data for every bus station. The research has successfully developed a prototype of AR mobile applications. An analysis of interactivity and benefits of TRANSPAR has shown that $90 \%$ agreed on the use of AR and more than $76 \%$ has agreed on its functionality based on 50 taken samples. This shows a positive impact on the designed TRANSPAR. The research is significant to encourage the public with a new technological application for public transportation that impacts society.
\end{abstract}

Keywords - augmented reality, unity 3D, image marker, smart bus transportation, mobile application

\section{Introduction}

Transport is a fundamental activity both for industry and for society. Todays's smart city development has transformed people into digital societies which made the life of its citizens easy in every aspect. An intelligent transport system becomes an important part of every city. In any city mobility is a key concern either going to school, college, and office, or for any other purpose, people use the transport system to travel within the city. Providing citizens with an Intelligent Transport System can save their time and make improve the city. Smart Transport System (STS) aims to obtain traffic efficiency by better managing traffic problems [1]. It provides users with traffic information beforehand, which reduces the travel time of commuters and improves their experience including their safety and comfort. Over the years, public bus transportation 
has become an integral part of society. However, it seems that the long due issue with the public bus has never been resolved. Long waiting times, unsafe locations of the bus stop, and lack of service at a major tourist spot are some common public complaints about the bus transportation system. The disruption of bus service is one of the major concerns. Though society are become digitally connected and the world is moving towards IR4.0, the bus service providers are still unable to rely on real-time and responsive information on the bus schedule and routes. The traditional bus numbering system also confuses the new passenger as they were not informed of the bus number, designated route, and destination. This has caused more trouble for both bus operators and bus passengers as it affects the planning and operation of buses. A study has been made that shows an algorithm for comparing the time-distance accessibility based on the movement data of actual transportation networks and analyzing resulting accessibility distributions to overcome the problem [2]. Another way of optimizing is done by synchronizing train and bus timetables and bridging their services to create a steadier flow [3]. However, the previous studies focus more on the solution for the transport operator on the route distance algorithm or a smart schedule timetable. It is scarcely found any solution to provide better quality transportation services to the users except the study on mobile ticketing solution and smart transportation tracking system using GPS [4]. A study has designed a tangible interface for virtual object manipulation in table-top Augmented Reality (AR) based on the Vuforia solution inspired by city planning AR solution. This AR technology enables bus passengers to access the realtime bus schedule and navigate the bus route more effectively. Most importantly is the user can seamlessly manipulate in 3-Dimensional (3D) structures that are displayed as virtual objects along the bus route [5].

Scheduling and route management is important for the operating scales of public transport providers. It is difficult to meet the market demand on the fast-expanding volume of intercity passengers, the idler of bus dispatches, and proper route management systems [6]. There are different modes of transportation like buses, taxis, trains, and planes, but monitoring and recommending vehicles are still a challenge and that is why public transports are less attractive and neglected by people. This influences the people to use their vehicles which in turn increases the traffic. One study proposes a monitoring and recommendation technique based on GPS data set to overcome this problem [7]. One research used IoT and RFID technology to manage routes and track bus movements to allow the analysis of the traffic where the system can track each registered bus in the area crossing at the stops, which contains an RFID tag with bus information taken care of with RFID and current location is taken care with GPS [8]. Mobile AR applications are recent technology that has a strong potential for development in future trends. Taking a direction towards urban planning and transportation systems have made use of the capabilities of AR technology. The mobile phone is becoming increasingly advanced. With the addition of multiple sensors, embedded cameras, and powerful processors, new applications and user experiences have become accessible [9]. A considered mobile AR (MAR) enabled device, the device must be able to provide access to the location and specifics of the area. This is to allow for accurate navigation, location, and proximity technology for the defined context. A high graphic capability can be applied in many areas such as entertainment, navigation, and information for the user interface $[10,11]$. Most of the mobile AR solution are in education $[12,13]$, tourism $[14,15]$, healthcare $[16,17]$ and lifestyle [18] and information support [19]. Therefore, 
more research needs to be conducted to find the best mobile AR techniques especially in the context of smart transportation. AR in public transportation has been developed to help communities. Mass transit is on the rise globally and smart cities are being implemented by governments around the world, AR has the power to transform public transport with a self-supporting network for millions of travelers [20]. AR technology in the public transportation system would greatly improve the operations and it is also more practical than implementing in-vehicle navigations [21].

This research developed a mobile AR that uses a smartphone that adds integration between digital data and real-life to the real world upon request. Therefore, this AR solution has virtually worked anywhere. Ideally, the user has used the mobile phone's camera to scan marker images that enable the application to recognize which location of the current bus stop. This has triggered the 3D image of a notifier popup to appear on the camera's screen. The augmented is interactive, where the users can view different bus routes and schedules that pass through that bus stop. The data from the AR application are stored on Google Cloud Storage for easier accessibility and ease of use. This application improved the community to experience with technological applications which are easy to access.

\section{Design and architecture of TRANSPAR}

\subsection{Research flowchart}

Figure 1 shows the flowchart for the system. The designed AR provides real-time information about bus schedules and timings. The application called TRANSPAR uses specific image markers located in bus stops to display what number of buses runs through that stop, alongside its timings and other stops along its routes. The smartphone camera is used as the image scanner and processed to choose which pre-loaded frame before connecting to the database to view the timetable. The camera can capture the target image, then digital images are placed onto the environment that is being viewed by the smartphone's camera. The 3D is designed and model using Unity 3D. There are many techniques for AR developed applications such as using marker-based technique [22], line segment based algorithm [23], or image marker or scanner object [24]. A 3D model that is responsive and interactive will be shown on the device's screen when users interacted with the timetable to show more details about a specific route. As the users scan different markers at different bus stops, the generated timetable is according to the routes that run at each stop specifically. Android smartphone programming is designed by using Android Studio. Google's Cloud Storage is used to stored data and information from Unity 3D and Vuforia. The 3D model data and marker information and programming code are also stored on the cloud storage. This has made the application easier to access from anywhere with an internet connection. The users have easier access to the application for the updating process. The step is first, the user needs to start the camera from their smartphone. The camera then searches for an AR marker. The AR marker is set up in the form of images at the bus stops. When the camera detects the marker, a 3D model for the corresponding marker is loaded and layered onto the camera's display, creating an augmented environment with the 3D model. The camera pickups for a different location then the $3 \mathrm{D}$ model for the corresponding marker is overlaid onto the 
environment while the previous 3D model disappears. All the data for the application is stored on Google Firebase Console. If the user chooses to use the markerless option, there is an available menu for the bus timetable is to be displayed on the screen.

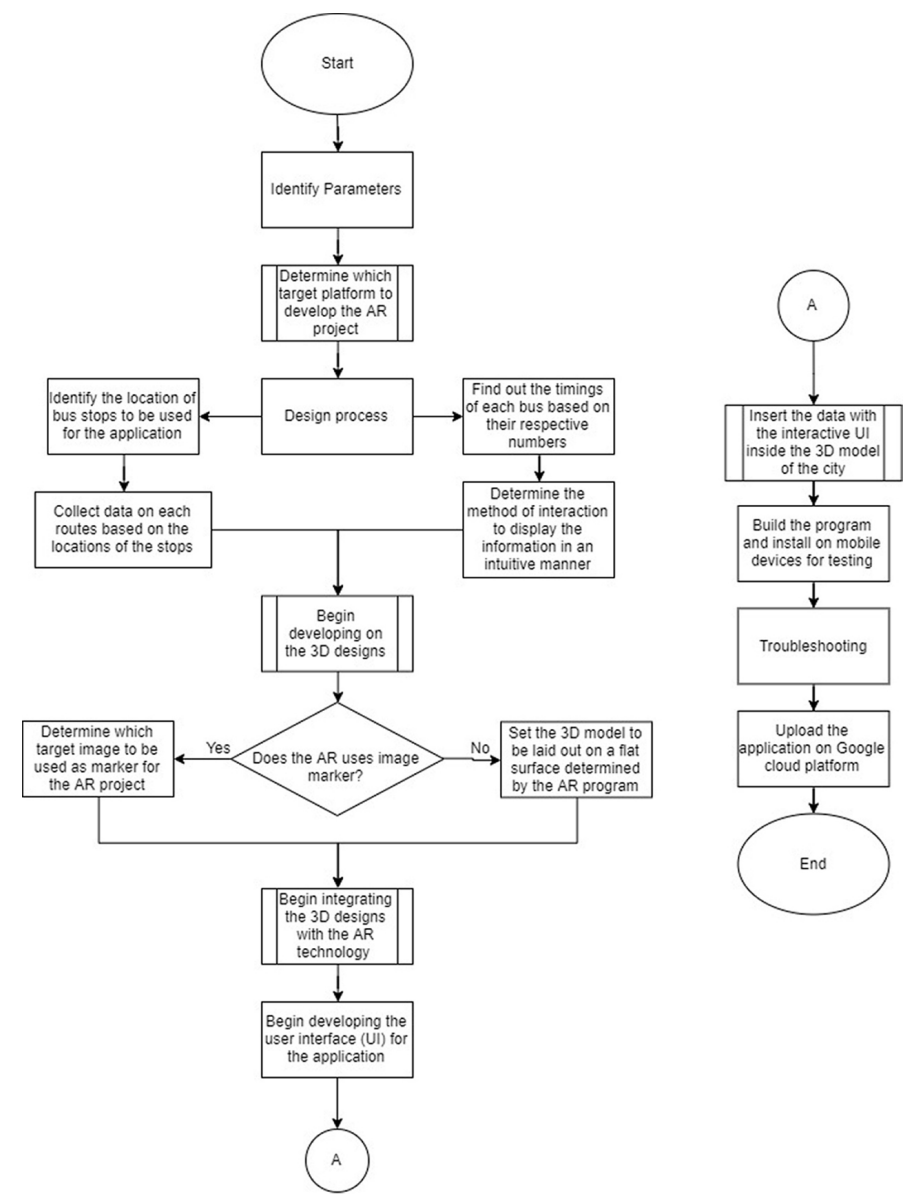

Fig. 1. System flowchart

\subsection{System architecture design}

Figure 2 shows how the user interface is designed through Unity3D which is users' friendly and easy to use. Markers were designed and set as each location has its unique to differentiate each other. The AR application is installed on the smartphone and the device's camera acts as a detector to recognize the AR target image. Vuforia is the image processor to detect and render AR objects. The 3D model of the target assigned marker is shown onto the device's camera when the target image is detected. The model is responsive and can be interacted with the device. The model will identify the GPS, routes, and schedules data on the application. All data and information from the AR application were stored on Google Cloud Storage. This architecture is a derivation 
based on previous AR implementation towards integrating real-world experience with $3 \mathrm{D}$ objects. Figure 3 shows as mobile phones are used as the platform in which the AR application is installed. A menu navigation layout has been designed using unity $3 \mathrm{D}$ and the timetable to display the bus schedules. Vuforia AR tool is added to add the AR element into this application which makes the 3D AR timetable. Figure 4 shows the timetables being made into 3D objects to be attached to each image target. Figure 5 shows the online database using a cloud firebase real-time database. Firebase also provided collaborative and immersive experiences without the networking code. The firebase real-time database can be accessed directly from a mobile device or web browser which is no requirement for an application server. Security and data validation are available through the firebase real-time database security rules and expression-based rules that are executed when data is read or written. The prototype design used in this research development is categorized into two, the user interface and database.

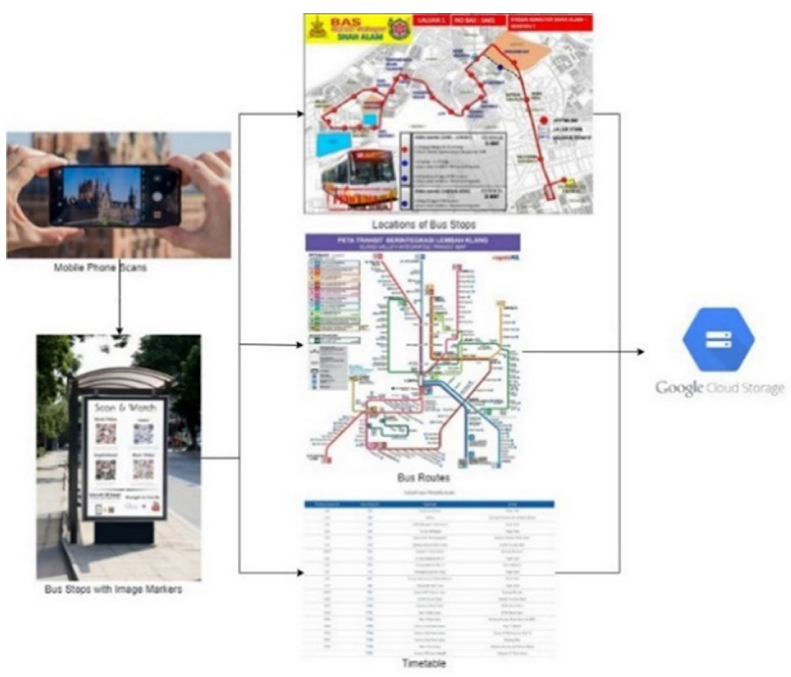

Fig. 2. The TRANSPAR architecture design

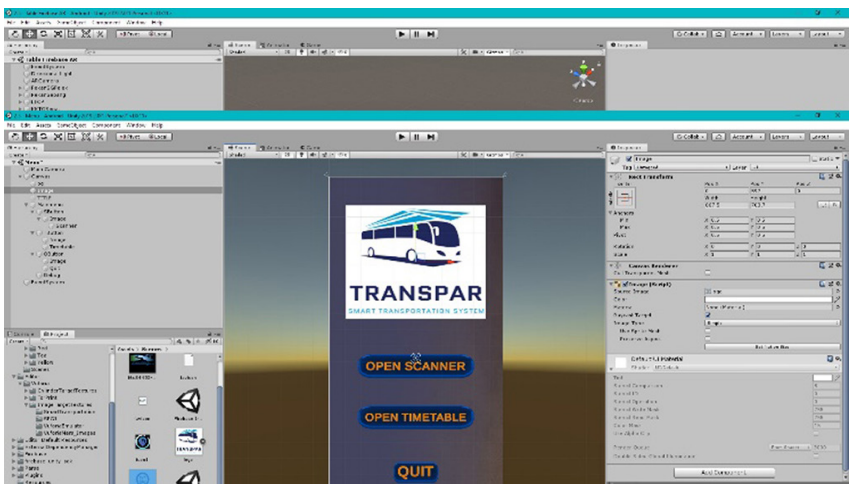

Fig. 3. Menu and interface design using unity 


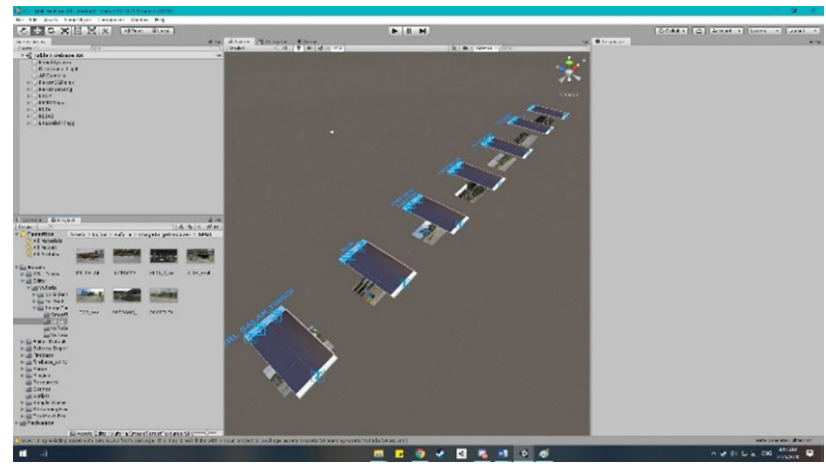

Fig. 4. Design on 3D timetable image

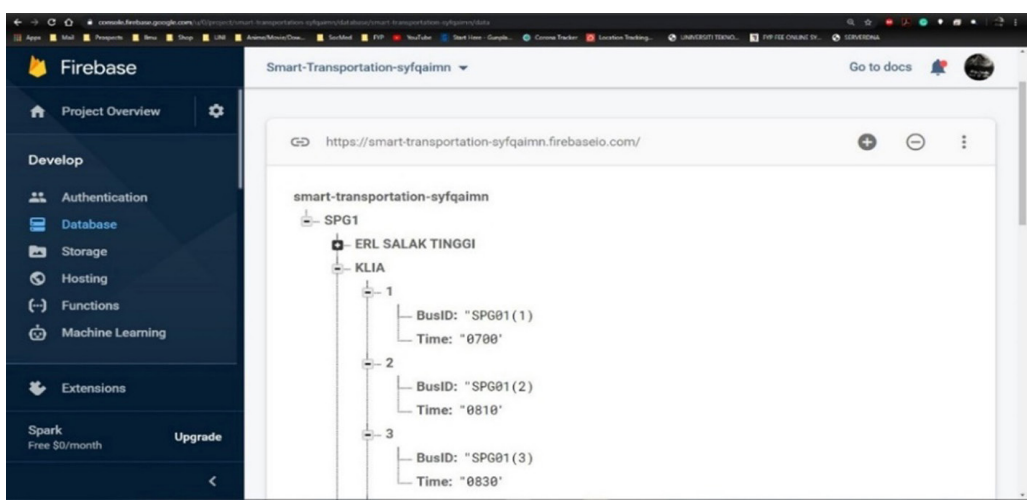

Fig. 5. Firebase realtime database console user interface

\section{$3 \quad$ Result and discussions}

This research has successfully created an AR application that provides an interactive 3D timetable for the bus routes. An analysis of the use of the prototype has been analyzed. A smartphone is used as the AR application platform where a camera is used to detect the AR image target. Digital images are placed onto the environment that is being viewed by the smartphone's camera when the camera captures the target image. The device's screen will show the rendered model that can be interacted and users can scroll through the timetable and find their timings. This has created a portable bus route directory and useful information about the bus routes. This system also could obtain the latest information if changes happened as the data for the application is stored on Google Cloud Storage. The 3D models are then represented in the AR characteristic concept to visualize the notification board. Another one is to create an AR platform on android Mobile phones to link to the information bus route and times. 


\subsection{Prototype of TRANSPAR}

TRANSPAR application on the mobile phone is developed that shows an AR application for acquiring the bus timetables. The smartphone's camera is used for AR object scanning and tracking of the AR target image. Two (2) menus were designed in TRANSPAR. A Scanner Mode implements the AR element in the application where the users scan the target image and the real-time timetable showing the bus routes appear as a AR 3D object in their phones. Figure 6 shows the AR timetable on local images of the target locations. It is being taken to be used as a marker for the 3D AR object. Figure 7 shows some of the target images for this application and each of them was placed at their bus stops, respectively. Normal Mode shows an unlisted image by the camera as AR but still wants to know the bus times. The third menu is an option to manually search the bus stop and bus schedule as shown in Figure 8.

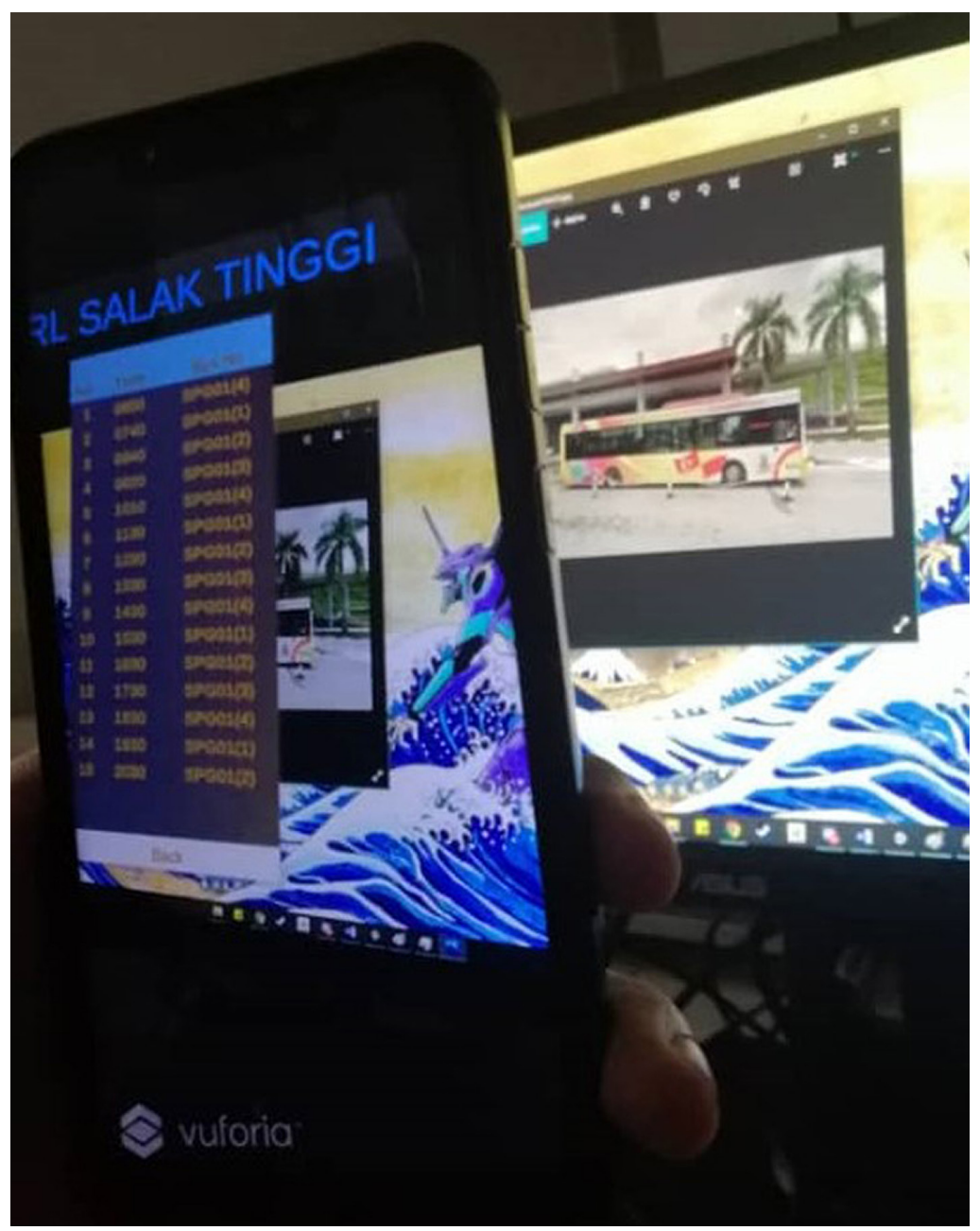

Fig. 6. AR timetable in use with the marker image 


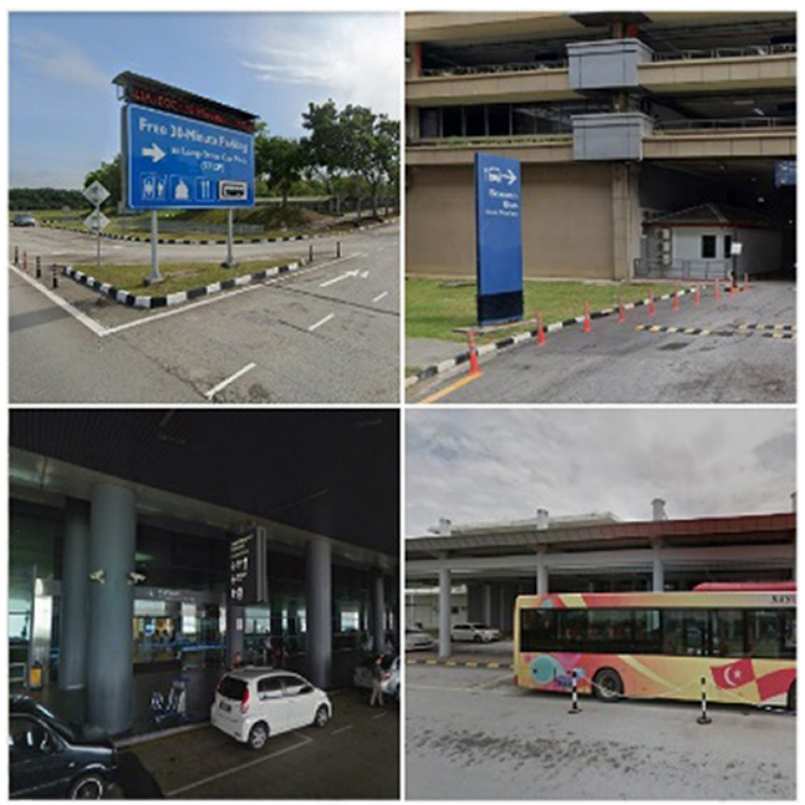

Fig. 7. Image markers

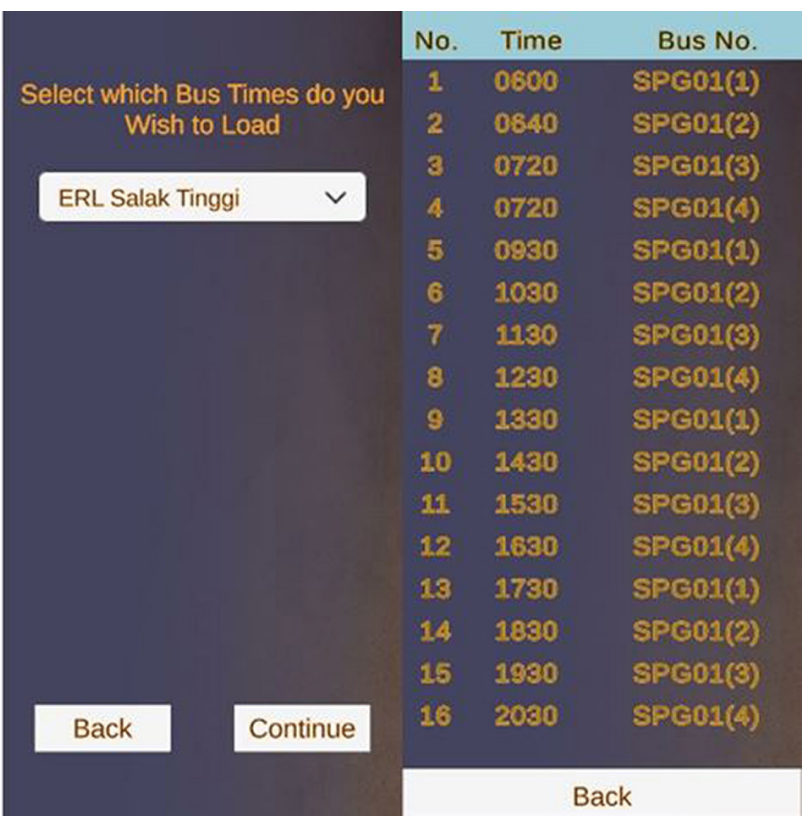

Fig. 8. Normal mode 


\subsection{Analysis of the TRANSPAR}

The TRANSPAR AR prototype has been analyzed and 50 users have participated were chosen to test out the TRANSPAR application. Their feedback is then measured using a questionnaire via Google Forms. The data is then analyzed and represented to observe the overall scale of this application. The questions comprised of their experience in using a transportation application, type of application used, and the frequency of their public transportation use. Figure 9 shows that $40 \%$ of the user's age group is between 26-30 years old. This indicates that most of the users in this sample group either students or fresh graduates. Figure 10 shows $44 \%$ of the users use Waze as their main transportation application. The least is a red bus which indicated that the current bus application is not very popular which a newer with better technology application is needed. Figure 11 presents that $30 \%$ of the users used the bus more than 20 times a month. This shows that most users used the bus as their mode of transportation. Users' feedback surveys that cover multiple aspects such as time spent using TRANSPAR, TRANSPAR usability, interactivity, user interactivity, and how much they rate the TRANSPAR application has been analyzed. Figure 12 shows $58 \%$ of the users strongly agreed that it is easy to use TRANSPAR. This shows that the application is functional and easy to use which overall gains approval from the public. Figure 13 shows 100\% of all the users agreed that the application timetable is useable. This shows positive feedback on application functionality. Figure 14 shows $90 \%$ of the users agreed that the application helps them to find the bus timetables. The result shows positive feedback on TRANSPAR's main functionality.

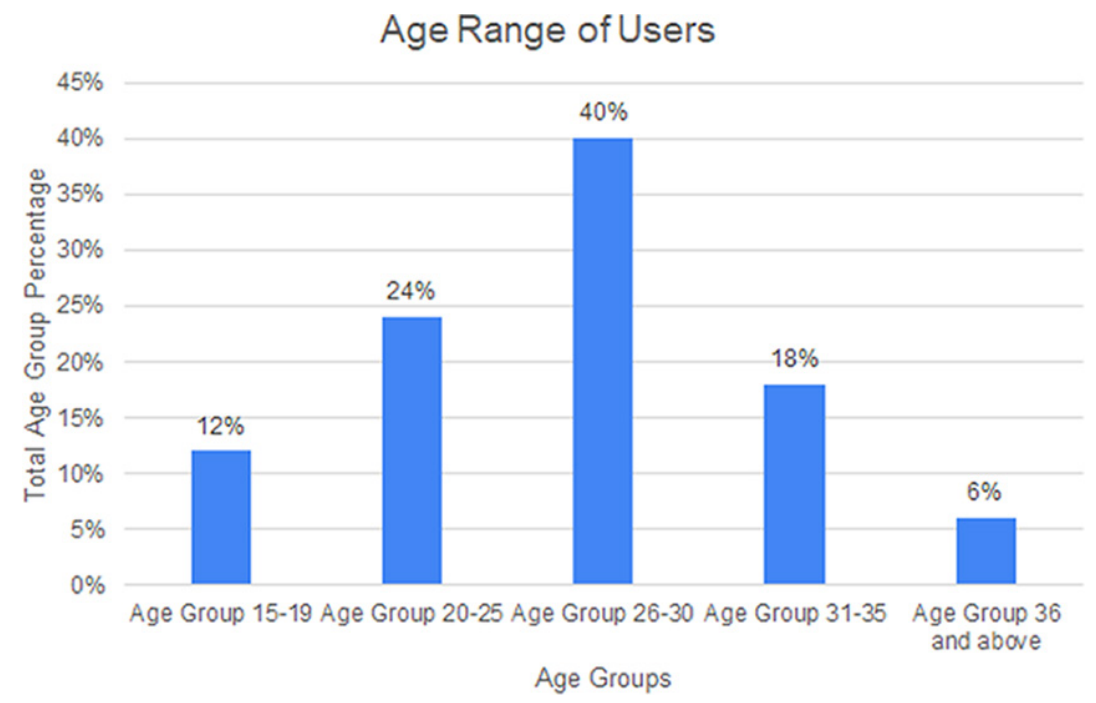

Fig. 9. Frequency of bus usage 


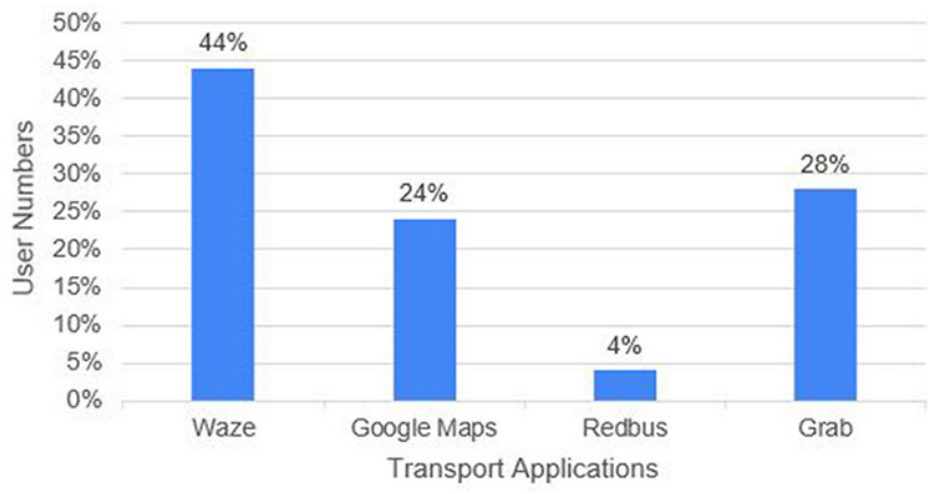

Fig. 10. Transport applications used

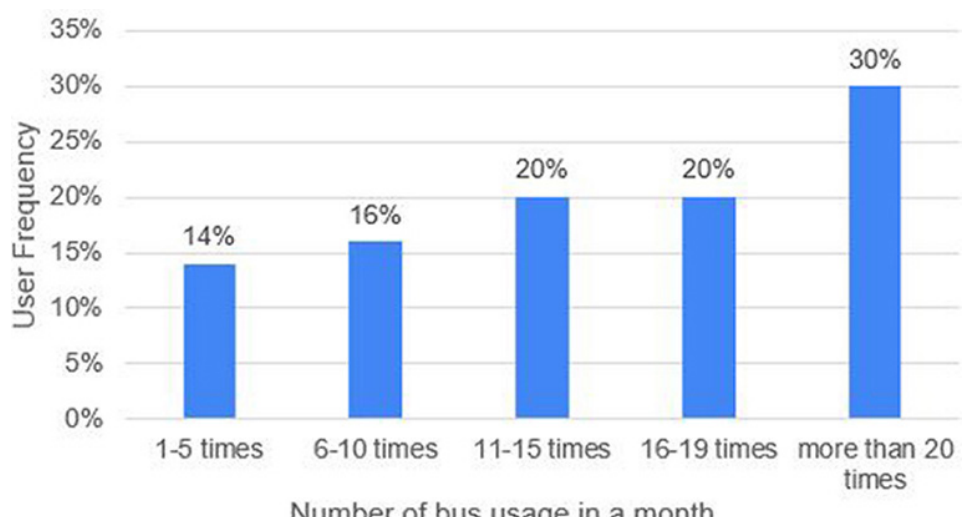

Number of bus usage in a month

Fig. 11. Number of bus usage

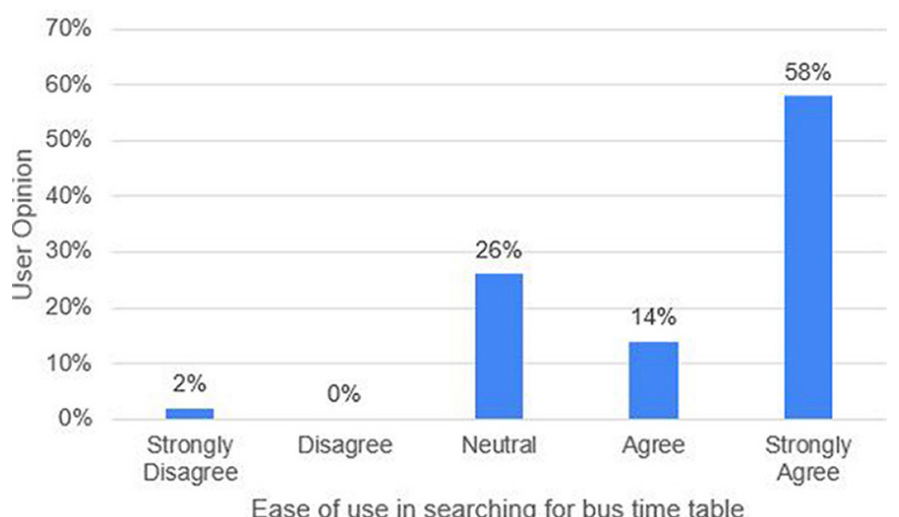

Fig. 12. User experience 


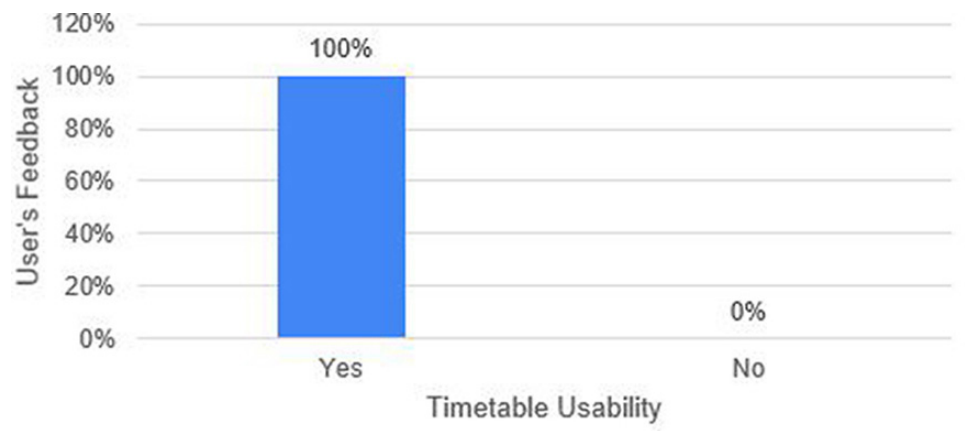

Fig. 13. Timetable usability

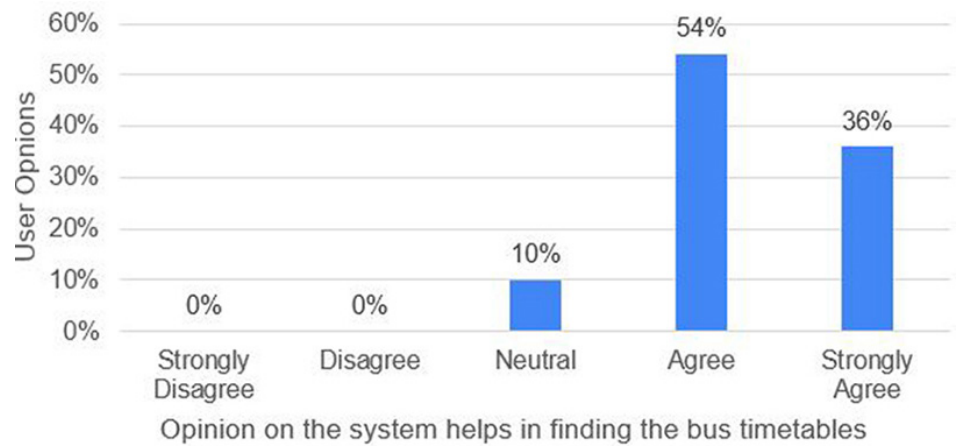

Fig. 14. Helpfulness of the application

The usability of the application has been analyzed based on the user's experiences with TRANSPAR. A Likert scale from 1 to 5 is used in the questionnaire. Users were asked about their time spent on the application, user-friendliness, ease of access, and their AR experience on using TRANSPAR. Figure 15 shows $76 \%$ have agreed on their experiences in using AR applications. Analysis shows that AR has the potential on being the future of transportation and information delivery. Figure 16 shows $94 \%$ have agreed that the menu system in this application is interactive. This indicates that users can easily navigate through the application functions. Figure 17 shows $96 \%$ of the users agreed on the AR functions in this application. This shows positive feedback on AR technology applied to this application. 


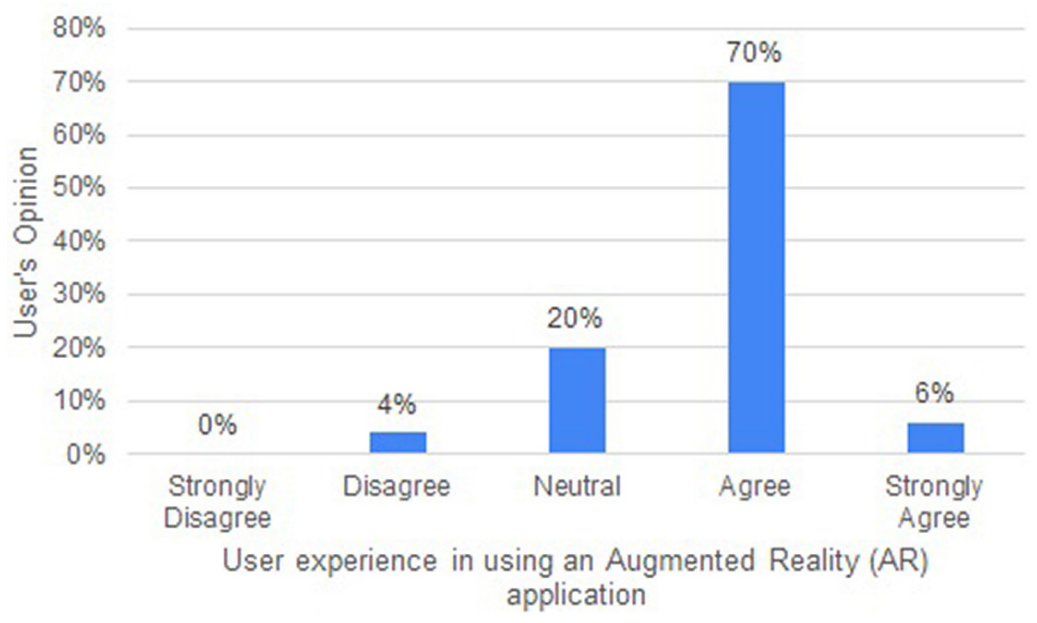

Fig. 15. User experience in AR application

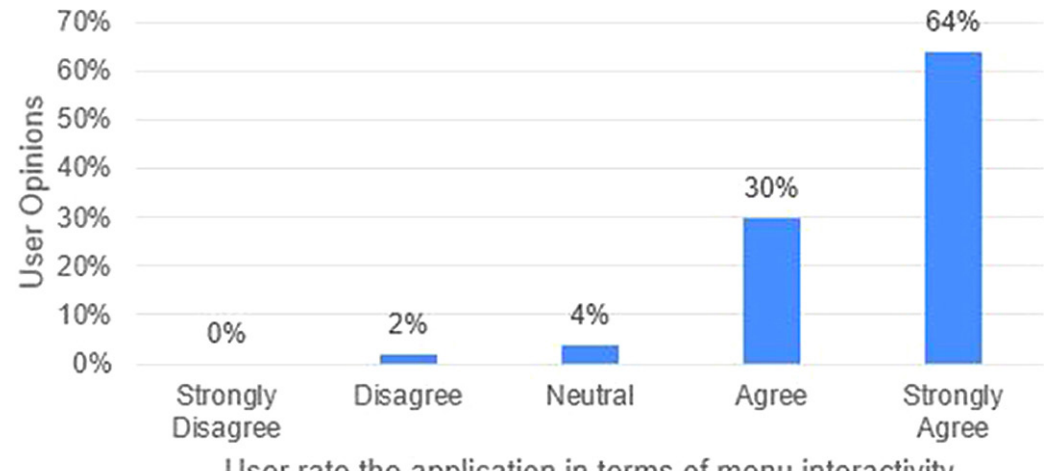

User rate the application in terms of menu interactivity

Fig. 16. User opinion on menu interactivity

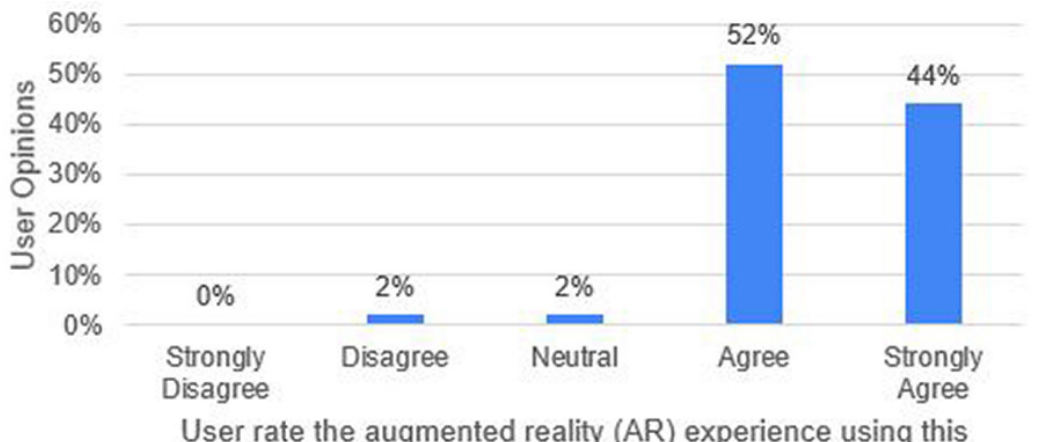

User rate the augmented reality (AR) experience using this application

Fig. 17. User AR experiences 
This segment aims to obtain the user's opinions on TRANSPAR and AR apps. This section gauges the user's opinion on the overall usability, opinion, and the application helpfulness based on their perspective. Figure 18 shows 54\% agreed that it helps to plan their routes when using this application. This shows that the application support society to properly plan their journey when taking a bus. Figure 19 shows the result in $52 \%$ agree that they would recommend this application to others. This shows that this application is beneficial to society and provides many benefits to the community.

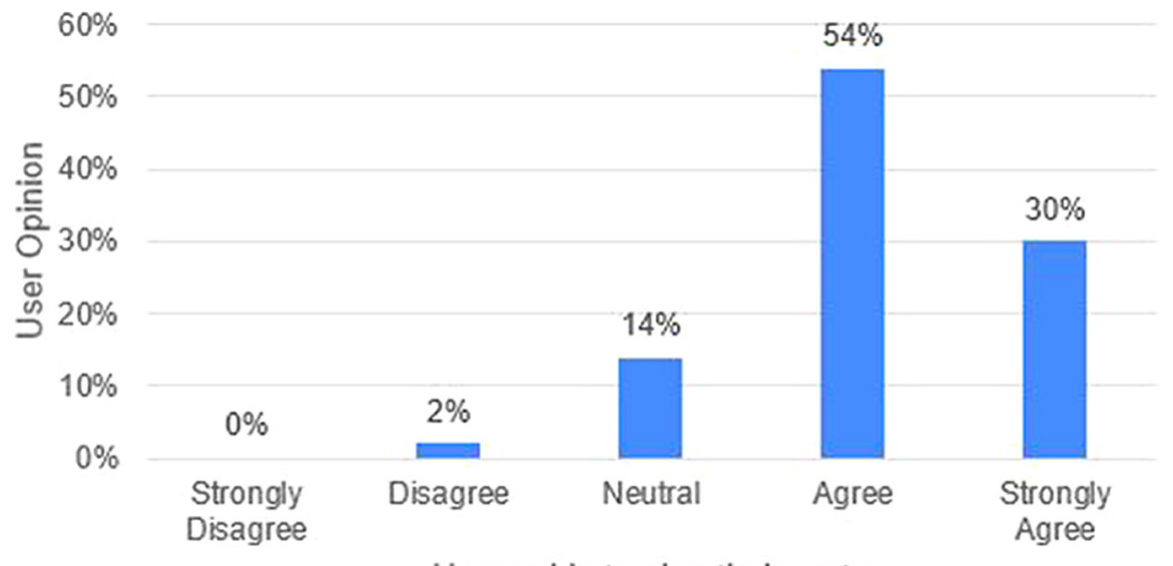

Users able to plan their route

Fig. 18. Users route planning

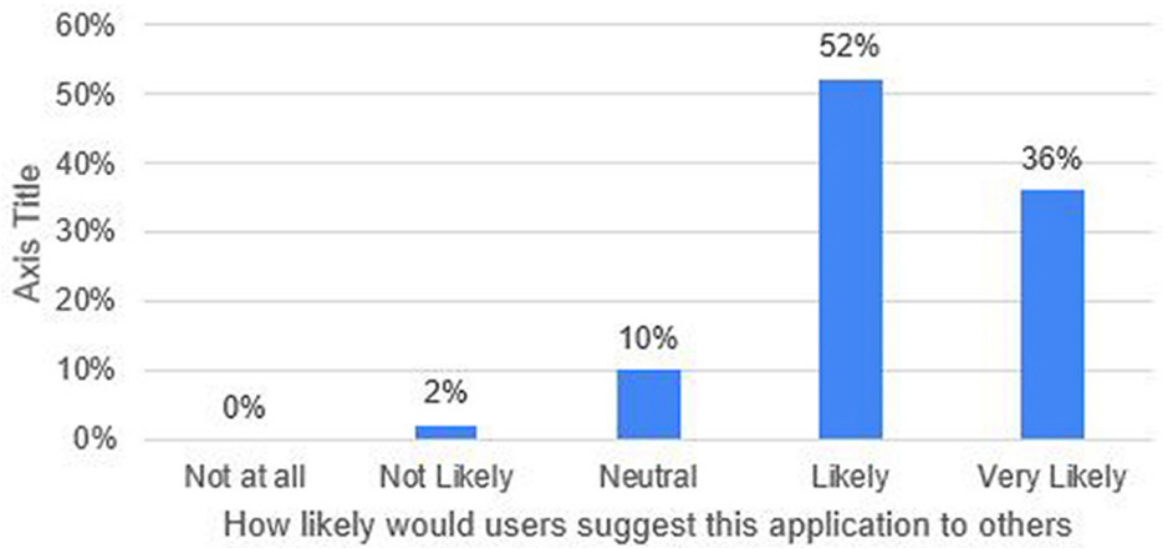

Fig. 19. User recommendation of this application 


\section{Conclusion}

Augmented Reality (AR) is considered one of the most sophisticated technologies in virtual reality research and effective as a medium for information, especially in navigation and tourism. This research has successfully developed a mobile prototype called smart bus transportation using augmented reality (TRANSPAR). The AR has successfully shown the information of the bus route and times in a city or area. Analysis on the use of TRANSPAR has shown that users satisfaction on $100 \%$ of users agreed that the application timetable is useable. More than $90 \%$ agree on the usability of the AR menu and its functions. This research is significant where AR is becoming a popular technology in which more systems to support social development system that holds the potential for the society. The developed TRANSPAR also is beneficial to secure that the tourism sector with the current technology. This research can encourage the public to use more public transportation as its impact on society itself. In conclusion, this research is essential for the enhancement of city navigations.

\section{Acknowledgement}

The authors would like to thank the Research Management Institute (RMI), Universiti Teknologi MARA, UiTM Shah Alam for the support grants in publishing this research.

\section{References}

[1] M. Abbasi, M. Rafiee, M. R. Khosravi, A. Jolfaei, V. G. Menon, and J. M. Koushyar, "An efficient parallel genetic algorithm solution for vehicle routing problem in cloud implementation of the intelligent transportation systems," Journal of Cloud Computing, vol. 9, no. 1, 2020, Art no. 6, doi: https://doi.org/10.1186/s13677-020-0157-4.

[2] Y. D. Ko and B. D. Song, "Sustainable service design and revenue management for electric tour bus systems: seoul city tour bus service and the eco-mileage program," Journal of Sustainable Tourism, vol. 27, no. 3, pp. 308-326, 2019, doi: https://doi.org/10.1080/09669582. $\underline{2018.1560453 .}$.

[3] L. Kang, X. Zhu, H. Sun, J. Wu, Z. Gao, and B. Hu, "Last train timetabling optimization and bus bridging service management in urban railway transit networks," Omega, vol. 84, pp. 31-44, 2019, doi: https://doi.org/10.1016/j.omega.2018.04.003.

[4] S. H. Sutar, R. Koul, and R. Suryavanshi, "Integration of Smart Phone and IOT for development of smart public transportation system," in 2016 International Conference on Internet of Things and Applications, IOTA 2016, 2016, pp. 73-78, doi: https://doi.org/10.1109/ IOTA.2016.7562698.

[5] D. Rohendi and Y. Wihardi, "Learning three-dimensional shapes in geometry using mobilebased augmented reality," International Journal of Interactive Mobile Technologies, vol. 14, no. 9, pp. 48-60, 2020, doi: https://doi.org/10.3991/ijim.v14i09.13035.

[6] S. W. Li et al., "Flexible bus route setting and scheduling optimization adapted to spatial-temporal variation of passenger flow," Sensors and Materials, vol. 32, no. 4, pp. 1293-1309, 2020, doi: https://doi.org/10.18494/SAM.2020.2554. 
[7] R. Gopinath and G. K. Shyam, "Monitoring and recommendations of public transport using GPS data," in Proceedings of International Conference on Computational Intelligence and Data Engineering, Springer, 2019, pp. 141-146, doi: https://doi. org/10.1007/978-981-13-6459-4_15.

[8] M. J. Shah, R. P. Prasad, and A. S. Singh, "IOT based smart bus system," in 2020 3rd International Conference on Communication Systems, Computing and IT Applications, CSCITA 2020 - Proceedings, 2020, pp. 130-134, doi: https://doi.org/10.1109/ CSCITA47329.2020.9137816.

[9] M. De Sá and E. F. Churchill, "Mobile augmented reality: a design perspective," in Human Factors in Augmented Reality Environments, Springer, 2013, pp. 139-164, doi: https://doi. org/10.1007/978-1-4614-4205-9 6 .

[10] M. Schickler et al., "Flexible development of location-based mobile augmented reality applications with AREA," Journal of Ambient Intelligence and Humanized Computing, 2020, doi: https://doi.org/10.1007/s12652-020-02094-9.

[11] N. Pradani, Munzil, and M. Muchson, "Development of guided inquiry based learning materials enriched with augmented reality in electrolysis cell material," International Journal of Interactive Mobile Technologies, vol. 14, no. 12, pp. 4-15, 2020, doi: https://doi. org/10.3991/ijim.v14i12.15597.

[12] G. Wu, M. Qiu, Y. Zhang, and Y. Zheng, "Research and development of augmented reality children's puzzle game based on vuforia," in 2019 14th International Conference on Computer Science \& Education (ICCSE), IEEE, 2019, pp. 354-359, doi: https://doi.org/10.1109/ ICCSE.2019.8845385.

[13] M. Kassim and M. T. H. Md Zubir, "Design of augmented reality for engineering equipment in education," International Journal of Advanced Trends in Computer Science and Engineering (IJATCSE), vol. 8, no. 6, 2019, doi: https://doi.org/10.30534/ijatcse/2019/15862019.

[14] R. Rahimi, A. Hassan, and O. Tekin, "Augmented reality apps for tourism destination promotion," in Destination Management and Marketing: Breakthroughs in Research and Practice, IGI Global, 2020, pp. 1066-1077, doi: https://doi.org/10.4018/978-1-79982469-5.ch059.

[15] Sudirman, Mellawaty, R. P. Yaniwati, and R. Indrawan, "Integrating local wisdom forms in augmented reality application: Impact attitudes, motivations and understanding of geometry of pre-service mathematics teachers', "International Journal of Interactive Mobile Technologies, vol. 14, no. 11, pp. 91-106, 2020, doi: https://doi.org/10.3991/ijim.v14i11.12183.

[16] M. Kassim and M. N. H. M. Said, "Data analytics on interactive indoor cycling exercises with virtual reality video games," in 2018 4th International Conference on Control, Automation and Robotics (ICCAR), IEEE, 2018, pp. 321-326, doi: https://doi.org/10.1109/ ICCAR.2018.8384693.

[17] H. F. Hanafi, M. H. Wahab, K. T. Wong, A. Z. Selamat, M. H. M. Adnan, and F. H. Naning, "Mobile augmented reality hand wash (MARHW): mobile application to guide community to ameliorate handwashing effectiveness to oppose Covid-19 disease," International Journal of Integrated Engineering, vol. 12, no. 5, pp. 217-223, 2020, doi: https://doi.org/10.30880/ ijie.2020.12.05.028.

[18] R. Alturki and V. Gay, "Augmented and virtual reality in mobile fitness applications: a survey," in Applications of Intelligent Technologies in Healthcare, Springer, 2019, pp. 67-75, doi: https://doi.org/10.1007/978-3-319-96139-2_7.

[19] S. Izzaty, H. Tolle, R. Dermawi, and F. Permana, "Augmented reality objects design in augmented story book mobile application for better engagement," International Journal of Electrical and Computer Engineering, vol. 9, no. 1, pp. 570-576, 2019, doi: https://doi. org/10.11591/ijece.v9i1.pp570-576. 
[20] K. Ikizawa-Naitou and K. Yamamoto, "A support system of sightseeing tour planning using public transportation in Japanese rural areas," Journal of Civil Engineering and Architecture, vol. 14, pp. 316-332, 2020, doi: https://doi.org/10.17265/1934-7359/2020.06.003.

[21] K. C. Brata and D. Liang, "Comparative study of user experience on mobile pedestrian navigation between digital map interface and location-based augmented reality," International Journal of Electrical and Computer Engineering, vol. 10, no. 2, p. 2037, 2020, doi: https:// doi.org/10.11591/ijece.v10i2.pp2037-2044.

[22] H. Subakti, H. Tolle, and M. Aswin, "Engfi gate: an indoor guidance system using marker-based cyber-physical augmented-reality," International Journal of Electrical and Computer Engineering, vol. 8, no. 1, pp. 34-42, 2018, doi: https://doi.org/10.11591/ijece. v8i1.pp34-42.

[23] V. Vani and G. R. Prasad, "An improved augmented line segment based algorithm for the generation of rectilinear steiner minimum tree," International Journal of Electrical and Computer Engineering, vol. 7, no. 3, pp. 1262-1267, 2017, doi: https://doi.org/10.11591/ ijece.v7i3.pp1262-1267.

[24] I.Tahyudin and D. I. S. Saputra, "A response analysis of mobile augmented reality application for tourism objects," International Journal of Electrical and Computer Engineering, vol. 7, no. 6, pp. 3500-3506, 2017, doi: https://doi.org/10.11591/ijece.v7i6.pp3500-3506.

\section{$7 \quad$ Authors}

Murizah Kassim is currently working as Associate Professor at the School of Electrical Engineering, College of Engineering, Universiti Teknologi MARA, Shah Alam, Selangor. She received her Ph.D. in Electronic, Electrical, and System Engineering in 2016 from the Faculty of Built Environment and Engineering, Universiti Kebangsaan Malaysia (UKM). She has published many indexed papers related to a computer network, Internet of Things, Web and Mobile applications research. She has experience for 19 years in the technical team at the Centre for Integrated Information System, UiTM. She is also head of Enabling Internet of Things Technologies (ElIoTT) research group UiTM. She joined academics in January 2009 and is currently a member of MBOT, IEEE, IET, IAENG, and IACSIT organization.

Ahmad Syafiq Aiman A Bakar obtained his first degree in Electronics Engineering from Faculty of Electrical Engineering, Universiti Teknologi MARA, Shah Alam, Selangor Malaysia in 2020. Previously, he obtained his first diploma from Universiti Teknologi MARA, Terengganu, in Electrical and Electronic Engineering. He is most experienced on the Internet of Things and Computer Engineering research development in his study.

Article submitted 2021-02-15. Resubmitted 2021-07-02. Final acceptance 2021-07-03. Final version published as submitted by the authors. 